\title{
Capture by Threat
}

\section{Citation}

Dal Bó, Ernesto, and Rafael Di Tella. 2003. “Capture by Threat." Journal of Political Economy 111 (5): 1123-54. https://doi.org/10.1086/376951.

\section{Permanent link}

http://nrs.harvard.edu/urn-3:HUL.InstRepos:41426663

\section{Terms of Use}

This article was downloaded from Harvard University's DASH repository, and is made available under the terms and conditions applicable to Other Posted Material, as set forth at http:// nrs.harvard.edu/urn-3:HUL.InstRepos:dash.current.terms-of-use\#LAA

\section{Share Your Story}

The Harvard community has made this article openly available.

Please share how this access benefits you. Submit a story.

Accessibility 


\section{Capture by Threat}

\section{Ernesto Dal Bó}

New College, Oxford

Rafael Di Tella

Harvard University

We analyze a simple stochastic environment in which policy makers can be threatened by "nasty" interest groups. In the absence of these groups, the policy maker's desire for reelection guarantees that good policies are implemented for every realization of the shock. When pressure groups can harass the policy maker, good policies will be chosen for only a subset of states of nature. Hence, honest and able leaders might implement bad policies, and needed reforms could be delayed. In order to make good policies more likely, the public will want to increase the cost of exerting pressure for "nasty groups" and provide rents to those in power. This last result can be used to explain the existence of political parties. They play a role resembling that of the supervisor in the literature on collusion in hierarchical agency. A rational public may also choose to ignore negative media reports on a politician's personal life and, in general, elect "strong" political leaders. The prevalence of coercive methods of influence helps explain why countries may get to be governed by "inept politicians."

In memoriam Guido Di Tella. We would like to thank the editor Pierre-André Chiappori, an anonymous referee, Mark Armstrong, Pedro Dal Bó, Juan Carlos Hallak, Meg Meyer, Barry Nalebuff, Santiago Oliveros, Julio Rotemberg, Andrei Shleifer, Jose Wynne, and participants at various seminars for very helpful discussions. An earlier version of this paper was circulated under the title "Democracy under Pressure: Political Parties vs. Nasty Interest Groups" and then under the current title as Harvard Business School Working Paper no. 041 (1999).

[Journal of Political Economy, 2003, vol. 111, no. 5]

(C) 2003 by The University of Chicago. All rights reserved. 0022-3808/2003/11105-0002\$10.00 


\section{Introduction}

A fundamental insight of the literature on capture is that policies that do not make much sense in economic terms may be playing a political role. The root assumption in this literature is that policy makers are dishonest (see, e.g., Stigler 1971; Peltzman 1976; Becker 1983; Baron 1989; Grossman and Helpman 1994; Besley and Coate 2001). In virtually every model that we know of, politicians voluntarily trade policies for money, either for themselves (bribes) or for the party (campaign contributions). There are at least three potential problems with this approach. The first is that it suggests that the election of a perfectly honest politician, however unlikely that may be, would lead to the selection of welfare-maximizing policies. Yet there are plenty of examples of reform processes in which seemingly honest and competent policy makers fail to implement good policies. Second, the assumption that interest groups influence policy only by offering money to politicians seems too restrictive and appears to leave out a wide range of empirical phenomena. For a start, politicians are (very) occasionally assassinated. In other cases, politicians are subject to costly legal harassment. This suggests that, when it comes to influencing politicians, pressure groups have a whole range of actions available to them that lie between giving them money and killing them. Finally, the activities of groups as modeled in the literature up to now (i.e., as bribe providers) always tend to increase the returns for politicians to being in office. The implication is that countries that experience more state capture should at least be able to attract policy makers of higher ability, something that is empirically questionable. The aim of this paper is to broaden the literature on interest groups to address these issues by developing a model in which groups use threats.

We present a model in which policy makers are completely honest. Our politician would never adopt a particular policy because bribes have been offered or campaign contributions have been pledged. ${ }^{1} \mathrm{He}$ does, however, have a weakness. He cares about his own and his family's wellbeing. The root assumption of the paper is that there are instances in which pressure groups can attempt to influence policy makers by threatening them. This is possible when these "nasty" groups develop ways to affect the policy maker's utility even when he has no interest in entering into a transaction with the group. ${ }^{2}$ The precise way in which groups threaten will depend on the environment. Physical violence is only the extreme case. More often pressure groups will be able to affect the good name of a politician by smear campaigns, starting negative rumors in

\footnotetext{
${ }^{1}$ For a model in which politicians are not necessarily incorruptible and the group uses bribes as well as threats, see Dal Bó, Dal Bó, and Di Tella (2002).

${ }^{2}$ The word "pressure" certainly has some nonvoluntary connotations. Thus it is possible to distinguish between "interest groups" and "pressure groups."
} 
influential groups through word of mouth. ${ }^{3}$ Sometimes pressure groups can attack the policy maker in the media. This can be done directly, by sponsoring advertisements personally attacking the politician, or indirectly, by supporting "independent" television and radio programs. Certainly part of the concern with concentration of ownership in the media industry is related to its considerable power to influence public opinion. ${ }^{4}$ Sometimes pressure groups can use the legal system to harass the politician. They can initiate litigation aimed at showing the illegality or administrative incompetence of the policies proposed by the policy maker. ${ }^{5}$ Or they can bring up accusations related to some real or fictitious crime. The reason why the pressure group may raise false accusations is that, even if justice ultimately prevails, significant damage can be done to the reputation and moral authority of the policy maker. Moreover, the accused politician may have to face lengthy and costly trials. In this case the instrument of punishment is the law itself. In Latin America this practice has become so common that it already has a name: the judicialization of politics (see, e.g., Sola 1998). In countries in which the judicial system can be influenced, pressure groups can affect the outcome of such trials, and even innocent politicians could be condemned. In other countries in which the cost of violence is low enough, pressure groups can use the threat of physical violence against the politician or his family in order to affect policy making.

Threats occur in our model in order to induce a given policy maker to change his action from that preferred by society to that preferred by the group. This includes situations in which the official yields to threats because he fears political damage, and not personal damage. The official may choose a bad decision after convincing himself that the realization of punishment, discrediting him or his political cause, may lead to his replacement, with candidates pursuing undesirable agendas thereafter. Groups could have at least two more reasons to use threats. First, if the group expects that punishment will lead to the official's removal, threat and punishment may occur just to allow a new, "better-disposed," in-

\footnotetext{
${ }^{3}$ Winston Churchill is said to have complained that "a lie gets halfway around the world before the truth has a chance to get its pants on."

${ }^{4}$ An article in the Economist (April 4, 1998) reveals that seven of Russia's eight largest financial-industrial groups have significant media interests. It also suggests that the main reason for the appointment of Viktor Chernomyrdin's successor as prime minister (Sergei Kiriyenko) in March 1998 was his ties to the country's business community: "Kiriyenko's industry pedigree may have recommended him to the leaders of Russian big business .... The approval of these tycoons is well worth having. They own most of the national mass media and much of the banking industry too. They can twist the arm or stain the reputation of any minister they choose" (pp. 56-57).

${ }^{5} \mathrm{~A}$ small literature in political science documents the activities of lobbyists. Schlozman and Tierney (1983) found that one of their most usual activities (undertaken by above 70 percent of the sampled lobbies-and growing) entailed "filing suit or otherwise engaging in litigation" (p. 357, table 1).
} 
dividual to take office. This is obvious in the case of direct violence that physically incapacitates the official. It also applies to cases of smear campaigns and legal harassment that lead to the policy maker's removal from office (resignation or sacking). Second, a group may attack the policy maker to render him less effective at pursuing agendas the group dislikes. One could assume that the policy maker has a stock of political capital that is diminished if a smear campaign forces him to spend time defending himself.

In our simple model, a perfectly honest political leader (call him president) must make a policy decision. His chances of reelection depend on this decision and an adverse shock. In the absence of nasty pressure groups, the president's desire to stay in power always leads him to choose the right policies for the country. When the pressure group is active, however, he chooses the good policy for only a subset of the realizations of the shock, a result that is related to those obtained in the literature on "delayed reform" (as explained below). In order to induce the selection of its preferred policy, the public can introduce a political party to accompany the president. As party members enjoy being in office and observe the choice of policy, they provide some protection to the president only if he chooses good policies. The equilibrium of this game has the size of the set of states of nature for which good policies are chosen depending on the vulnerability of the president, the cost of threatening him, and the amount of rents available to politicians while in office. The latter increases the desire of party members to retain office. People may also prefer a strong leader, not because they have an intrinsic preference for such individuals, but because strong leaders may be less vulnerable to the attacks of pressure groups. ${ }^{6}$

Our paper has a number of differences from the previous literature. First, we take steps toward a more realistic theory by allowing for the existence of honest policy makers and nasty interest groups. As a result, our model accounts for a number of phenomena and institutions frequently observed in reality that could never arise in the world described by the traditional economics literature on political influence. ${ }^{7}$ Second, the punishment activities analyzed here represent costs to both parties of the "transaction" and always involve deadweight losses, whereas bribes are essentially transfers. Furthermore, our paper provides an explanation for the existence of political parties. The previous literature on capture does not reserve a distinct role for political parties since they are assumed mainly to transmit the pressure of active groups (see, e.g.,

\footnotetext{
${ }^{6}$ As an example, we can expect that a politician who enjoys extramarital sex will be regarded by the public as a less convenient candidate.

"Przeworski (1991), e.g., opens the chapter "Transitions to Democracy" arguing that "the strategic problem of transition is to get to democracy without being killed by those who have arms" (p. 51).
} 
Becker 1983; Grossman and Helpman 1994). In our model the party is not just like any other pressure group since it is subject to electoral discipline and its members are given rents by the public while they hold office. Since we consider only one active interest group, the issue of competition among groups is not analyzed. In any case, the main points raised here can certainly be cast in terms of a common agency framework, with many political parties and pressure groups. Finally, and in contrast to previous work, when nasty pressure groups become active, the returns to being in office fall. Since the rewards to a job are often a reasonable proxy for the quality of its applicants, a simple prediction of our model is that state capture through pressure will be associated with policy makers of lower ability.

The literature offers some explanations for the existence of political parties. Weingast and Marshall (1988) provide a theory of legislative committees as an institution that helps enforce political transactions. They suggest that parties could play a similar role by building reputations that differ from those of the individuals who are affiliated with them. ${ }^{8}$ Also, an infinitely lived political party can help overcome the opportunistic tendencies or the lame-duck problems associated with a politician nearing the end of his term. Alesina and Spear (1988) emphasize the role of transfers in providing discipline, and Harrington (1992) focuses on a president who sticks with party policy to preserve the chance of seeing a like-minded politician setting policy in the future. ${ }^{9}$ Wittman (1989) mentions another potential rationale for political parties. When political candidates represent districts, there may be a tendency toward the implementation of too many pork barrel projects (as in Fiorina and Noll [1978] and Weingast, Shepsle, and Johnsen [1981]). The existence of a national political party could be a way to internalize the negative externalities that might arise when districts try to shift the cost of projects to other districts. In our model, political parties are there to monitor and protect the president. They have an incentive to do so because the public gives them rents when they are in office, and the chance that they remain in office depends on the president's policies. There are formal similarities between the role played by the political party in our setup and the role of the external (costly but noncollusive) supervisor in the hierarchical model of Kofman and Lawarree (1993) (see also Tirole 1992). The external supervisor observes what the internal one

\footnotetext{
${ }^{8}$ In Jones and Hudson (1998), party affiliation is a cheap way for a candidate to signal policies and abilities to the voter. Snyder and Ting (2000) offer a model in which parties discipline members and membership signals ideology. Caillaud and Tirole (2001) model the party as providing a governance structure that regulates competition among likeminded candidates.

${ }^{9}$ Shepsle and Nalebuff (1990) study parties as long-lived organizations made of overlapping generations of agents using the model in Cremer (1986).
} 
does, and this reduces the chances that the latter is captured. In our model, since party members observe everything the president does, they can make support contingent on the president's playing the good policy. This reduces the chance that the president is captured by the group.

The result that good policies will be chosen for only a subset of the states of nature can be related to the growing literature on economic reform. Two stylized facts in this literature are that reforms may be delayed and that a crisis is often needed to trigger them. In other words, reforms that appear to be beneficial to society are delayed far longer than seems justified, and when implementation finally occurs, it coincides with a deterioration of economic conditions. Alesina and Drazen (1991) explain delay noting that reform can be considered a public good and there could be a conflict-modeled as a war of attritionover how to distribute the burden of providing it. Fernández and Rodrik (1991) argue that nonadoption of a reform can occur because there is uncertainty about its benefits across individuals. Drazen and Grilli (1993) show how the onset of a crisis triggers reform. Our model of capture by threat provides an explanation for both stylized facts that differs from those in the existing literature.

Section II discusses some examples. Section III presents a simple model of policy making under nasty pressure groups. Section IV characterizes the policy-making equilibrium. Comparative statics results are shown in Section V. Section VI presents welfare considerations related to the desirability of having a system with political rents, and Section VII presents conclusions.

\section{Four Examples}

The following examples are four incidents in which, at one point or another, it has been suggested that pressure groups were trying to affect policy decisions. Two preliminary comments are worth making. First, it is not always the case that pressure groups were proved to be behind the incidents. For the purposes of our paper it is sufficient that somebody finds it plausible enough to argue in public that the attacks were organized by pressure groups. Second, in the case of accusations of corruption, whether the policy maker is guilty or not of the charges levied against him is not really relevant in determining whether the incident was used by the pressure group to affect policy. In terms of our model, the possibility that some accusations are true would simply reduce the cost of exerting influence for the pressure group.

Each year, a number of policy makers are assassinated around the globe. In some cases the deaths have been linked to pressure groups. A recent example concerns Galina Starovoitova, shot dead in St. Pe- 
tersburg in November 1998. In her obituary, commentators speculated on the reasons:

Now, Miss Starovoitova, perhaps the most ardent of the reformers, is dead, murdered, apparently by political opponents, and Mr. Yeltsin looks none too well....

... At the end of her lecture or radio interview, you were a little more aware of the reformers' struggle as they faced attacks by powerful groups "striving to restore the old economic and political system" and which sought to exploit the "ordinary Russians' nostalgia for communist times.” ...

A problem for her enemies was that she could not be bought. She lived simply and seems to have had no business interests. ["Obituary," 1998, p. 92] ${ }^{10}$

The second example takes us to Argentina in 1995, where the then-finance minister, Domingo Cavallo, denounced the existence of a Mafia in the mail industry. After revising the contracts of state-owned enterprises with one of the mail companies, he was accused of wrongdoing and, initially, successfully prosecuted for corruption. Cavallo was found guilty of the charge of "failure to comply with the duties of a public servant" for lowering the price paid by the Banco Hipotecario (publicly owned) to the private mail companies by almost one dollar per letter (from $\$ 1.40$ to $\$ 0.45$ for each letter). Although he was later cleared of any wrongdoing by the court of appeals, his reputation was damaged with the least informed members of the public, and he ultimately faced very large legal bills. That this was part of a campaign and not a spontaneous, freak event is perhaps suggested by a famous threat, made years earlier by one of Cavallo's political adversaries, that he "would get tired of visiting Tribunales" (the building that houses the central legal offices in Argentina). ${ }^{11}$

The third example involves the case of military coups. In some regions, notably Latin America, the armed forces have traditionally been a very active pressure group. One of the most interesting cases concerns

\footnotetext{
${ }^{10}$ Keesing's Record of World Events, News Digest for February 1998, documents other assassinations in eastern Europe, Africa, Asia, and Latin America, where it has been alleged that pressure groups have been involved. It also records unsuccessful assassination attempts, such as that of Georgia's president, Eduard Shevardnadze, in February 1998: "Shevardnadze also expressed his belief that the attack might have been an attempt to destabilize the country at a time when consortia extracting oil from the Caspian Sea were debating whether to export the oil through a pipeline across Georgian territory or via an alternative route" (p. 42084).

${ }^{11}$ Other incidents in which policy makers have been accused of corruption and have claimed to be under attack by antireform pressure groups include those of Pakistan's former prime minister, Benazir Bhutto, and Mexico's former president, Carlos Salinas de Gortari.
} 
Chile in 1973, where President Salvador Allende was deposed in a military coup by General Augusto Pinochet. Allende's explicit socialist ideology and policies, such as land reform and nationalizations in the banking and mining industries, triggered the uprising of the Chilean armed forces with the explicit support of a part of Chilean society. The case of Chile points out that other countries may choose to support local pressure groups. According to recently declassified Central Intelligence Agency (CIA) documents, the United States supported Pinochet's coup. Apparently the motivation for these actions was to limit Allende's "ability to implement policies contrary to US and hemisphere interests." 12

Our fourth example concerns the impeachment of President Bill Clinton in 1999. A number of observers have seen in the behavior of the media the influence of pressure groups. With some variations, the basic story argues that pressure groups that suffered under Clinton's policies actively sought to increase the cost of the Monica Lewinsky affair for him, not because they thought it had any bearing on social welfare, but because they were seeking for a way to punish him for his policies. For example, conservative religious groups in the Christian Coalitionwhich disliked Clinton's approach to abortion and gay rightsdistributed pamphlets criticizing the bad example he set for the rest of society. Others have seen the influence of corporate America. Gore Vidal (1998) provides an account of one such theory in his article in the Observer (London). ${ }^{13}$ Although his presidency survived the impeachment, President Clinton faced very large legal bills. Some time later it

\footnotetext{
${ }^{12}$ These documents are now public. Cable News Network Interactive reports that "one of the CIA documents states that the US had a 'firm and continuing policy that Allende be overthrown by a coup' and speaks of the need for 'the American hand to be wellhidden' in such an act" ("Why Is the US Mum about Pinochet?" [November 25, 1998]). In National Security Archive Electronic Briefing Book no. 8 ("Chile and the US: Declassified Documents Relating to the Military Coup" [1998; archived at George Washington University]), there are handwritten notes of the CIA director at the time registering President Richard Nixon's orders to "make the economy scream." For a highly conspiratorial account of the U.S. involvement in the coup against President Jacobo Arbenz Guzmán of Guatemala in 1953 and the role of the United Fruit Corp., see Schlesinger (1982).

${ }^{13}$ Vidal states that "Mrs Clinton is correct when she says that there is a right-wing conspiracy against them. Unfortunately for her, Americans have been trained by the media to go into Pavlovian giggles at the mention of the word 'conspiracy' .... Mrs Clinton, perhaps, emphasises too heavily the 'right-wing' aspect of her enemies. It is corporate America, quite wingless in political as opposed to money matters, that declared war on the Clintons in 1993, when the innocent couple tried to give the American people a national health service .... In order to destroy the health service plan, insurance and pharmaceutical companies, in tandem with lively elements of the American Medical Association, conspired to raise a half billion dollars to create and then air a barrage of TV advertisements to convince the electorate that such a service was communist .... Then, not content with the political destruction of the Clintons' health plan, corporate America decided to destroy their reputations."
} 
was revealed that Bill and Hillary Clinton had difficulties in buying a house since they were "indebted by $\$ 5$ million in legal bills, and have slightly more than \$1 million in assets" (Van Natta 1999, p. B1).

\section{The Model}

A certain society is subject to adverse shocks, denoted $\theta$. We assume that the distribution of $\theta$ over $[0,1]$ is described by the function $\Lambda(\theta)$, with associated density $\lambda(\theta)$, and that we have $d \lambda / d \theta \equiv \lambda^{\prime}<0$ for all values of $\theta$ (i.e., small shocks are more likely than large ones).

This society must make a policy decision denoted by $P$, delegated to an elected official (called president). This decision can be "good," in which case we have $P=P^{G} \equiv 1$, or it can be "bad," in which case we have $P=P^{B} \equiv 0$. Throughout the paper, "good" policies will be taken to mean policies that are popular (i.e., they are preferred by the majority of the population), whereas "bad" will mean the opposite, as in redistributive policies that take money from, say, 90 percent of the population and give it to a pressure group.

Both the shock and the policy decision are not observable by the public. For concreteness we can think of a country in which the standard of living is subject to a productivity shock and the president must privatize a state-owned steel company. The price obtained for the company is uninformative about the value of $P$ since there are unobservable aspects of the transaction. For example, the president can leave a high or a low level of inventories. Observing a low price, we could be in the presence of a president who has left few inventories or a president who has been captured by the threats made by some potential buyer and is leaving a high level of inventories inside the company. ${ }^{14}$ All that citizens observe is their standard of living.

The public has the possibility of voting on the government's performance. Individual voters have limited incentives to gather information since they have a negligible impact on the outcome of the elections. We assume, however, that the government's performance (in terms of good or bad policies) has some impact on the government's probability of reelection. Since adverse shocks and bad policy reduce voters' welfare, we assume that both increase the probability that the government fails to get reelected, which is denoted $F(\theta, P)$. The function $F(\theta, P)$ is con-

\footnotetext{
${ }^{14}$ A low price and a high level of inventories is a bad policy because it is a giveaway, as is a high price and a low level of inventories because it will fail to attract bidders. Obviously, this setup can be extended to deal with cases in which policy actions are fully observable and the public remains uncertain about the consequences of policies.
} 
tinuously differentiable and increasing in $\theta .{ }^{15}$ We assume that $F(0$, $P)=0$ and

$$
\frac{\partial F\left(\theta, P^{B}\right)}{\partial \theta} \equiv F^{\prime}\left(\theta, P^{B}\right)>\frac{\partial F\left(\theta, P^{G}\right)}{\partial \theta} \equiv F^{\prime}\left(\theta, P^{G}\right)>0 .
$$

(Primes will denote partial derivatives throughout. To abbreviate notation, we define $\Delta F(\theta, P) \equiv F\left(\theta, P^{B}\right)-F\left(\theta, P^{G}\right)$ and $\Delta F^{\prime}(\theta, P) \equiv F^{\prime}(\theta$, $\left.P^{B}\right)-F^{\prime}\left(\theta, P^{G}\right)$.) The fact that $\Delta F(\theta, P)$ is monotonically increasing in $\theta$ means that, in terms of votes for the government, it really pays to deliver good policies in bad times. ${ }^{16}$

The president is accompanied by a group of persons who will perform auxiliary (ministerial) tasks. They are in office whenever the president is voted in, and they keep their positions in government as long as the president does. Henceforth, these people are called "the political party," and we assume that they observe whether the president chooses the good policy. All we require is that there be two actors in office, the president and the party, so we can think of the party as being formed by one person. The extension to a party with $N$ members is straightforward.

There is one pressure group in our society. We shall focus on situations of conflict between the interests of this group and those of society at large. Thus bad policies $\left(P^{B}\right)$ yield revenue $\Pi>0$ to the pressure group, whereas the adoption of good policies $\left(P^{G}\right)$ yields zero. In order to exert influence over policy, the pressure group punishes with intensity $j$ a president who chooses $P^{G}$. This level $j$ is an intensity of punishment focused exclusively on the president and is exercised through legal, media, or violent means. The punishment is activated only if the president chooses the good policy, and it never affects the party directly.

\footnotetext{
${ }^{15}$ This way of introducing electoral competition is consistent with previous literature. See Ledyard (1984) for a model with probabilistic features and fully rational individuals. Coate and Morris (1995) consider citizens whose role at monitoring policy makers is explicitly considered. Our formulation can be seen as the reduced form of a richer model in which citizens update their perceptions on the government upon observations of their own welfare. Welfare, which affects reelection chances, depends on both the choice of policy and the realization of a shock.

${ }^{16}$ Policy making when groups use threats can be studied with other assumptions about the effects of policy on electoral forces. But the present formulation emerges naturally if voter utility is concave in income and a reform represents a fixed income gain that is valued more when income is low (bad times). It is also plausible empirically. For example, Cutler and Gruber (2001) argue that the deterioration of health coverage due to the 1990 recession created a social demand for health reform during the Clinton administration. They say that "it is an ironic feature that the Administration's successful effort to promote macroeconomic growth helped to kill one of its signature social insurance programs" (p. 19). In a different context, it is often argued that reform in former socialist states, including those undertaken by socialist governments (e.g., Cuba), has been advanced when central planning became too costly in the face of adverse international prices and environmental and health degradation in the late 1980s (see, e.g., U.S. Congress 1989).
} 
The public does not observe punishment. When it does, it is unable to relate it to the activities of the group. This punishment costs the pressure group an amount $C(j)$, with $C^{\prime}(0)=0, C^{\prime}(j)>0$, and $C^{\prime \prime}(j)>0$ for all $j>0$. Pressure groups invest in punishment technology in advance by developing contacts with the media, buying judges, or hiring thugs. This order of play does not drive the results, but it simplifies the analysis and also rules out credibility problems: if the policy has already been (irreversibly) chosen, investing in punishment is a dominated strategy for the pressure group. ${ }^{17}$

The president and members of the political party derive utility from holding office. The president derives $m$, a number that includes his wage and the moral satisfaction of serving the community. Members of the political party receive $w$ while in office. We normalize to zero the president's and the party members' reservation utility, which implies that there are rents to the political class in office when $m$ and $w$ are positive. When $w>0$, members of the party would like to stay in power, so they offer an amount of protection $s$ to the president in order to induce him to adopt $P^{G}$ and increase the chances of reelection. Protection is given in order to mitigate the effects of the pressure group's attacks, and it is conditional on the choice of the good policy and on the occurrence of attacks of the pressure group. It costs $K(s)$, with $K^{\prime}(0)=0, K^{\prime}(s)>0$, and $K^{\prime \prime}(s)>0$ for all $s>0$. For concreteness, protection will be taken to be pecuniary, as when the party gives money to a president who has to pay bodyguards or legal fees arising from judicial harassment. ${ }^{18}$ Again, for simplicity and to eliminate credibility issues, protection is committed in advance.

\section{Timing of the Game}

The order of play is as follows.

Stage 1.-(a) The pressure group chooses an amount of punishment $j$ for a president who plays $P^{G}$ and zero otherwise. (b) Simultaneously, the party chooses protection payment $s$ for a president who plays $P^{G}$ and zero otherwise. (c) Simultaneously, nature draws $\theta$ from distribution $\Lambda(\theta)$.

Stage 2.-(a) The president learns $\theta$ and chooses policy P. Punishment

\footnotetext{
${ }^{17}$ The literature on interest groups largely ignores credibility problems. Grossman and Helpman (1994), e.g., analyze a two-period model in which lobbies choose political contributions in the first period and the government sets policy in the second. Lobbies pay if the government delivers, although after it delivers there are no incentives for the lobbies to pay. See also Baron (1989).

${ }^{18}$ Clinton was reported to get help in cash from Terry McAuliffe, a sympathizer who "is also raising millions for the Clintons' legal defense fund." The Clintons "sought financial assistance from former Treasury secretary Robert Rubin and two former White House chiefs of staff" (see Van Natta 1999, p. B1).
} 
and protection are activated if $P=P^{G} \cdot{ }^{19}(b)$ Elections are held. The president and the incumbent party are reelected with probability $1-$ $F(\theta, P)$.

\section{The Problem of the President}

The president's expected utility is given by

$$
E U=[1-F(\theta, P)] m-(j-s) P .
$$

Thus we restrict attention to politicians who are completely honest and will not accept bribes or campaign contributions. The president still cares about reelection because he receives a higher payoff in this job than in any other. If he wins, an event that will happen with probability $1-F(\theta, P)$, he stays in office as president and gets $m \cdot{ }^{20} \mathrm{He}$ also cares about the amount of punishment the pressure group inflicts on him, net of the protection received from the party. We shall denote net punishment (or harm) by $h \equiv j-s$. The president cares about net punishment in an additive fashion. It follows from the assumptions that his expected utility is monotonically decreasing in $\theta$ and that it decreases more when the bad policy is in place (i.e., $0>\partial E U\left(P^{G}\right) / \partial \theta>$ $\left.\partial E U\left(P^{B}\right) / \partial \theta\right)$. Note that if $h=0$, there is no shock realization that makes the president choose $P^{B}$. Things change for higher levels of net punishment, though. Lemma 1 summarizes an important property of the solution to the president's problem.

Lemma 1. (a) Any positive level of net punishment $h$ has an associated cutoff value $\hat{\theta}$ such that the president chooses $P=1$ if $\theta \geq \hat{\theta}$ and $P=$ 0 if $\theta<\hat{\theta}$. (b) The value $\hat{\theta}=\hat{\theta}(h)$ is a continuously differentiable, monotonically increasing function. ${ }^{21}$

Proof. See Appendix A.

The president's strategy can be fully characterized by $\hat{\theta}$, the value of the adverse shock for which he chooses to switch policy. This determines the size of the set of states of nature for which the president chooses the bad policy and provides us with a measure of the amount of "distortion" present in policy making. It can also be interpreted as a measure of "expected delay" until the adoption of the good policy and used to

\footnotetext{
${ }^{19}$ Some policies have a preventive rationale and must be implemented by the president before the shock is realized. Think of decisions concerning sanitary plans or the extent to which anti-earthquake building codes are enforced. Sometimes these decisions must be made before epidemics or earthquakes strike. Our model can accommodate these cases if there is a signal that is informative about the density from which the shock will be drawn. The main results in our paper also survive making protection contingent on the shock. They are also robust to making punishment contingent on the shock.

${ }^{20}$ All we require is that the president strictly prefers his party to win the election.

${ }^{21}$ Linearity of $F(\theta, P)$ in $\theta$ and $F(0, P)=0$ allow us to write $\hat{\theta}=h / \Delta F^{\prime}(\theta, P) m$, where $\Delta F^{\prime}(\theta, P)$ is now the difference between two scalars.
} 
address the issues raised in the literature on delayed reform. A larger $\hat{\theta}$ means that unpopular policies will be chosen more often (more on this below). Part $b$ suggests that the size of the set of states of nature in which the president chooses the bad policy will be increasing in net punishment.

\section{The Problem of the Pressure Group}

The pressure group's expected payoff is given by

$$
\Lambda[\hat{\theta}(h)] \Pi-C(j)
$$

where $\hat{\theta}=\hat{\theta}(h)$ is known to the pressure group and positive revenues occur only when the bad policy is adopted, something that lemma 1 suggests will happen with probability $\Lambda[\hat{\theta}(h)]$. For simplicity, revenues $\Pi$ are assumed to be independent of the realization of the shock. Thus, with protection taken as given, the first-order condition (FOC) is

$$
\lambda[\hat{\theta}(h)] \frac{d \hat{\theta}}{d h} \Pi-C^{\prime}(j)=0
$$

The pressure group will increase the punishment intensity as long as the expected marginal return of such an action is greater than its marginal cost. The expected marginal return is the product of three terms: (i) $d \hat{\theta} / d h$ (positive from lemma 1 ) is the marginal increase in the set of states of nature in which the policy most preferred by the group is implemented, as a result of a marginal increase in punishment; (ii) $\lambda(\hat{\theta})$ is the change in the probability that this policy is implemented; and (iii) $\Pi$ is the revenue gain in such a case. The second-order condition (SOC) is shown in Appendix B. ${ }^{22}$

The preferred level of punishment will be related to the amount of protection the party is willing to provide.

Lemma 2. (a) There exists a continuously differentiable function $\hat{j}=\hat{j}(s)$ for all $s \in[0, \bar{s}], \bar{s}>0$. It can also be verified that $d \hat{j} / d s \in(0$,

${ }^{22}$ Assuming that the function $F(\theta, P)$ is linear in $\theta$ ensures that the FOC selects a maximum, and $\lambda(\theta)$ decreasing in $\theta$ rules out the possibility of multiple solutions to (1). Most of the analysis can be carried out without these assumptions. One difference is that with nonlinear $F(\cdot)$, the SOC is not always satisfied unless one assumes $C^{\prime \prime}$ to be high enough. Moreover, when $F(\theta, P)$ is nonlinear in $\theta, \hat{\theta}(h)$ is nonlinear in $h$, and the comparative statics become quite cumbersome. 
$1), j^{\circ} \equiv \hat{j}(0)>0$, and $\hat{j}(s)>s^{23}$ (b) The best response of the pressure group is given by

$$
\breve{j}= \begin{cases}\hat{j}(s) & \text { for } s<\bar{s} \\ 0 & \text { for } s \geq \bar{s} .\end{cases}
$$

Proof. See Appendix A.

The intuition for this lemma is as follows. When the party is not insuring the president, the pressure group's best response is to choose a positive level of punishment, $j^{\circ}$. For higher protection levels provided by the party, the pressure group increases punishment, but not one for one. The reason is that higher levels of punishment are assumed to be increasingly costly. The lemma also shows that it could never be a best response for the pressure group to have a punishment level that equals the protection committed by the party. The induced distortion would be zero, which is what the group can attain by not incurring any punishment costs. That means that whatever the level $\bar{s}$ is, $\hat{j}(\bar{s})$ has to be strictly larger than $\bar{s}$. Finally, we establish that there must exist such a level $\bar{s}$ above which the best response of the pressure group is zero punishment.

\section{The Problem of the Political Party}

Once in office, the party has to decide the amount of protection it will give a president who chooses the good policy and is punished by the group. Hence, taking $j$ as given, the party chooses $s$ to maximize

$$
\int_{0}^{\hat{\theta}(h)}\left[1-F\left(\theta, P^{B}\right)\right] w \lambda(\theta) d \theta+\int_{\hat{\theta}(h)}^{1}\left[1-F\left(\theta, P^{G}\right)\right] w \lambda(\theta) d \theta-K(s) .
$$

The first two terms capture the expected return when policy $P$ is played, taken across all states in which it will be observed if protection is $s$. Reelection is desirable to the party in direct proportion to the rents it enjoys in power. In other words, for $\theta<\hat{\theta}$, the party takes part in one lottery with prizes zero and $w$ and probabilities $F\left(\theta, P^{B}\right)$ and $1-F(\theta$, $\left.P^{B}\right)$. For $\theta>\hat{\theta}$, the lottery has the same prizes but a higher probability of yielding the higher prize. The FOC can be written as

$$
\Delta F(\hat{\theta}, P) \lambda(\hat{\theta}) \frac{d \hat{\theta}}{d h} w-K^{\prime}(s)=0 .
$$

The party trades off the expected value of enlarging the set of states in which it takes part in its most preferred lottery against the cost of an

\footnotetext{
${ }^{23}$ Furthermore, for any positive $\Delta F^{\prime}(\theta, P) m$, assuming $\lambda(1)$ to be low enough guarantees that $\hat{j}$ is such that $\hat{\theta}$ is lower than one.
} 
extra unit of protection. The first term says that the marginal rise in protection will enlarge the interval $[\hat{\theta}, 1]$ 一the set of shocks in which a good policy is chosen-by an amount $d \hat{\theta} / d h$ (equal to $-d \hat{\theta} / d s$ ). This will improve the prospects of electoral competition facing the party with probability $\lambda(\hat{\theta})$. This improvement has value $\Delta F(\hat{\theta}, P) w$. On the cost side, the second term shows the marginal cost of raising protection. The SOC for this problem appears in Appendix B.

Lemma 3. There exists a continuously differentiable function $\hat{s}(j)$ satisfying $\hat{s}(0)=0$. If marginal returns to protection are decreasing in equilibrium, it can be verified that $d \hat{s} / d j>0$ and $d \hat{s} / d j<1$.

Proof. See Appendix A.

The best protection response grows less quickly than punishment because $j$ affects the marginal returns to protection (the first term on the left-hand side of [3]) only through $h$. This implies that, in terms of returns to protection, any increase in the punishment produced by the pressure group can be neutralized by an equal rise in protection. However, since the marginal costs of protection are increasing in $s$, it will not be convenient for the party to seek to totally undo the effects of the extra punishment.

\section{The Equilibrium}

\section{The First-Stage "Pressure" Game}

The pressure group and the political party compete to influence the president by using punishment and protection. The following proposition summarizes the outcome from such competition.

Proposition 1. (a) If $\hat{s}^{-1}(\bar{s}) \geq \hat{j}(\bar{s})$, the first-stage game between the pressure group and the political party has a unique Nash equilibrium in pure strategies. This equilibrium has $\left(s^{*}>0, j^{*}>0\right)$. Otherwise, there is no equilibrium in pure strategies. (b) The equilibrium in pure strategies, if it exists, always involves a positive level of net punishment: $h^{*} \equiv j^{*}-s^{*}>0$.

Proof. See Appendix A.

Figure 1 illustrates this. Figure $1 a$ shows a case in which reaction functions intersect. The features of these functions imply that such an intersection can happen only above the 45-degree line. Therefore, equilibrium always implies a positive level of net punishment. Figure $1 b$ shows a case in which there is no equilibrium in pure strategies. ${ }^{24}$ We shall, however, restrict attention to pure strategy equilibria.

\footnotetext{
${ }^{24}$ Equilibrium behavior in this case will involve mixing (which is also compatible with positive harm on the president).
} 

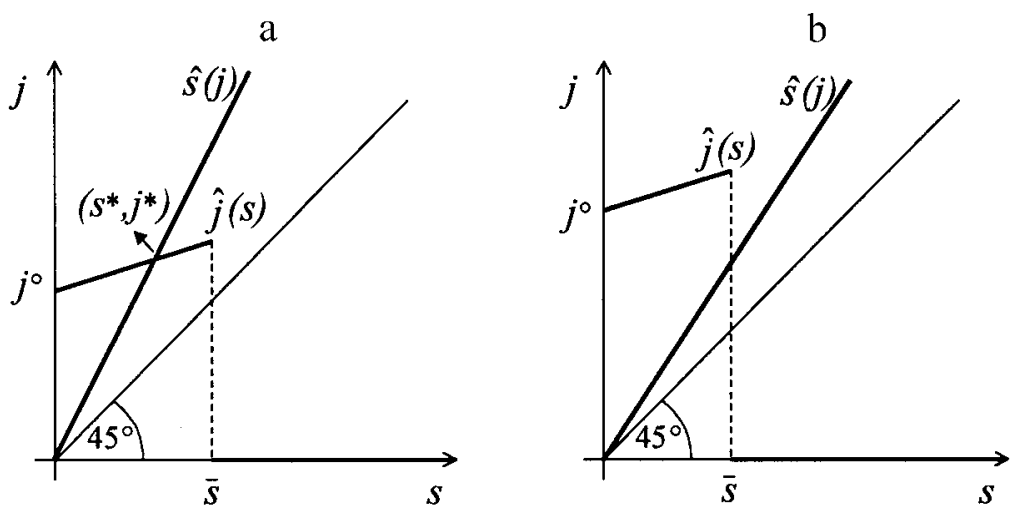

Fig. 1.-The "pressure" game

The Second-Stage "Policy Implementation" Game

Given an equilibrium $\left(s^{*}, j^{*}\right)$ in the first-stage game, we can think of the president simply using the function $\hat{\theta}(h)$ to determine a value $\theta^{*} \equiv \hat{\theta}\left(h^{*}\right)$.

Proposition 2. (a) Given an equilibrium $\left(s^{*}, j^{*}\right)$ in the first-stage game, there always exists a unique solution to the president's problem given by $P^{G}$ if $\theta \geq \theta^{*} \equiv \hat{\theta}\left(j^{*}-s^{*}\right)$ and $P^{B}$ if $\theta<\theta^{*} \equiv \hat{\theta}\left(j^{*}-s^{*}\right)$. (b) Since $\theta^{*} \equiv \hat{\theta}\left(h^{*}\right)>0$, the equilibrium distortion is strictly positive.

Proof. See Appendix A.

The sense in which the equilibrium implies a distortion is that, with probability $\Lambda\left[\theta^{*}\right]>0$, the shock realization will belong to the interval $\left[0, \theta^{*}\right)$ and the unpopular policy will be implemented. In other words, there is a positive probability that bad policies are adopted even when politicians are honest, and the democratic process ensures that politicians seek to remain in office by playing good policies. The magnitude $\theta^{*}$ is thus a measure of political failure (to implement good policies). Our result is due to the fact that net punishment must be positive in equilibrium. This, in turn, is due to two reasons. First, punishment cannot be zero. If it were zero, the party would provide no protection and the group would want to punish. Second, we know from lemma 3 that the party is in equilibrium only if the protection it provides to the president is lower than the punishment he receives.

Propositions 1 and 2 make four empirical contributions. First, the model explains why bad policies might emerge, even when the disciplining role of elections implies that an honest president would always prefer to choose good policies instead. Second, note that with probability $1-\Lambda\left[\theta^{*}\right]$, punishment is observed in equilibrium. Events such as smear campaigns, judicial harassment, or assassination are accountable 
as equilibrium outcomes in our model. Third, the result that good policies will be observed in only a subset of the states of nature represents an explanation for why reforms are delayed. This explanation differs from those previously offered in the literature (see, e.g., Alesina and Drazen 1991; Fernández and Rodrik 1991). Here, if the electoral gain to be derived from selecting the good policies is not too large, the president prefers to avoid the retaliation of a pressure group. Statistically, it will take time until the realized shock is in the category in which the electoral reward of the reform is larger than the personal cost of facing the punishment of the group. Finally, the prediction that good policies will be observed only for very bad realizations of the shock (i.e., only when $\theta>\theta^{*}$ ) is akin to the prediction that a crisis will make reforms more likely. This is of empirical interest since, as one of the main textbooks on political economy puts it, "The hypothesis that crisis induces policy change (or that crisis is necessary for a reform) has become, in the eyes of many, the new orthodoxy" (Drazen 2000, p. 444). ${ }^{25}$

\section{Discussion and Comparative Statics}

An element that implies a point of departure with previous work is the nonvoluntary nature of threats. Indeed, while a policy maker always has the option to just say no to bribes, he has little choice when it comes to threats of punishment. This is important because it changes the policy maker's expected payoff to being in office. In the traditional literature, since the policy maker can always refuse to trade with the group, his expected payoff has to be at least equal to the official wage. In other words, the presence of interest groups can only improve things for the policy maker (because in a simple world having an option can only make people better off). The same is not true when groups use threats. This is summarized in the following result.

Proposition 3. Inept politicians.-The expected payoff of the president is lower in the equilibrium with an active pressure group than in the equilibrium with an inactive pressure group.

Proof. See Appendix A.

The significance of this result can be seen by considering a simple extension of this model that allows for individuals of different ability levels. If there is free entry into politics and the returns agents get by working in the private sector are positively correlated with their ability, the presence of nasty pressure groups reduces the quality of applicants

\footnotetext{
${ }^{25}$ Drazen (2000) also surveys the empirical literature. Lora (1998), e.g., studies economic and political determinants of economic reform (such as privatization or the lowering of trade barriers) in Latin America for the period 1985-95. He finds that the best predictors of when reform will take place are the different measures used to capture the extent of macroeconomic crisis in the country.
} 
into the public sector. In other words, allowing for capture by threat is a way to explain why some societies get to be governed by low-ability people. This explanation for "bad politicians" is similar to that offered in Caselli and Morelli (2003) in the sense that society becomes supplyconstrained of good-quality candidates. It differs, however, in that in their model, as in all papers in the literature on interest groups that use bribes, the presence of interest group activity introduces a tendency for less inept politicians because groups are a source of supplementary income. ${ }^{26}$ The idea that interest group activity can only be positively correlated with the quality of politicians is empirically questionable. Our model offers the opposite prediction. This tendency to have low-ability policy makers in environments in which groups punish instead of give bribes is of interest because it could provide an explanation for why inefficient policies are sometimes used and why they may be observed in more violent environments (see also Coate and Morris 1995; Acemoglu and Robinson 2001).

\section{Changes Directly Affecting the Political Party and the Pressure Group}

We start with changes directly affecting first-stage players because they are simpler to analyze. In particular, we are interested in the effect of a change in the level of rents enjoyed by the political party $(w)$ when its members hold office. Since Becker and Stigler (1974), economists have argued that high wages in the bureaucracy could have positive incentive effects, especially when there is widespread bureaucratic corruption. Rents in our model, however, can be helpful even when policy makers are honest. Rents increase the desire of politicians to remain in power. This desire translates into more support (protection) from the party to the president and more resistance of the president against pressure. This suggests that strengthening the political system will induce better policies.

Proposition 4. An increase in rents given to the political party causes the equilibrium level of distortion $\theta^{*}$ to diminish.

Proof. See Appendix A.

The intuition for this result is related to the fact that the function $\hat{j}(s)$ has a slope less than one (in the $(s, j)$ space). If we start at a positive equilibrium level of net punishment $h^{*}$, higher rents induce higher protection for every level of punishment. This tends to be offset by an increase in the group's punishment. The increase is not one for one because the marginal cost of punishment is increasing.

\footnotetext{
${ }^{26}$ See Caselli and Morelli (2003) for a discussion of the selection of politicians along both honesty and ability dimensions.
} 
We are also interested in the effect of changes in the costs of punishment. Redefine the pressure group's objective function as

$$
\Lambda[\hat{\theta}(h)] \Pi-\beta Q(j),
$$

where the costs of punishment are now given by $\beta Q(j), Q(j)$ has all the properties so far attributed to $C(j)$, and $\beta>0$. The parameter $\beta$ is intended to capture elements affecting the cost of harassing the policy maker and can be tracked to issues such as what violence in society costs, how independent the judiciary system is, or how easy it is to influence the media.

Proposition 5. An increase in the costs of punishing the president will lead to a decrease in the equilibrium level of distortion $\theta^{*}$.

Proof. See Appendix A.

The proof of this result uses the fact that the slope of the party's reaction function is less than one and that a higher $\beta$ affects only the problem of the pressure group, leading it to prefer lower punishment levels. If the cost of punishing a president is related to the expected reactions of society about some aspects of his personality (sexual habits, say), it would be functional for society not to be too sensitive to these aspects. In our model, this would raise the cost of pressure and improve policy choices. In other words, it may pay not to be puritan. Countries in which extremism is active and some political accusations (e.g., of being communist or, alternatively, counterrevolutionary) are more credible naturally make smear campaigns more dangerous and offer a costeffective form of threat to the groups. In this connection, police states, countries in which witch hunts are being carried out, and other politically violent countries might then expect to see worse policies and lowerability politicians. Furthermore, if the costs of punishment decrease with the easiness with which groups can affect public opinion, this logic can be used to justify imposing some kind of restrictions on ownership across the media industry. This would help competition, making it more expensive to use this industry to affect policy. ${ }^{27}$

These results also give us some guidance as to which groups will be more likely to engage in capture by threat. Besides the media, examples include a country's security forces, which naturally have access to weapons; groups that control unions, which after enduring the vicissitudes of union democracy can turn their muscles to influencing politicians;

\footnotetext{
${ }^{27}$ An example is the recent debate in the Australian Parliament concerning media regulations. The report on the subject maintains that "the major effect of the laws is to prevent the common ownership of newspapers, television and radio broadcasting licences that serve the same region.... The justification for the rules is that the effective functioning of a democracy requires a diverse ownership of the daily mass media to ensure that public life be reported in a fair and open manner" (see http://www.aph.gov.au/library/intguide/ $\mathrm{sp} /$ media_regulations.htm).
} 
firms that litigate often and have repeated interactions with judges; public relations firms that allocate large advertising budgets in the media; and firms that control unoccupied areas (such as waste management companies) in which committing crimes and disposing of bodies are relatively simple.

Changes Directly Affecting the President

Rewrite the president's payoff function as

$$
E U=[1-F(\theta, P)] m-\frac{h}{v} P,
$$

where $m$ are the rents given to the president and the parameter $v$ provides a measure of the president's personal strength. Some countries provide policy makers with parliamentary immunity while they are in office. This protects them from legal harassment, at least temporarily. This institution tends to increase $v$.

Proposition 6. An increase in presidential rents, $m$, and an increase in the president's strength, $v$, both have ambiguous effects on the equilibrium level of distortion $\theta^{*}$.

Proof. See Appendix A.

The effect of an increase in parameter $x$ (where $x=m, v$ ) is given by

$$
\frac{d \theta^{*}}{d x}=\frac{\partial \hat{\theta}\left(x, h^{*}\right)}{\partial x}+\frac{\partial \hat{\theta}\left(x, h^{*}\right)}{\partial h^{*}} \frac{d h^{*}}{d x}
$$

The first term is a direct effect and is always negative. The sign of the second term is ambiguous. It depends on what happens to the protection-punishment pair. For low levels of $x$, we expect the direct effect to dominate. The indirect effect will reinforce the negative, direct effect whenever an increase in $x$ achieves a reduction in net punishment; this requires the density over shocks to be relatively flat around $\theta^{*}$. When this holds, both punishment and protection will decrease. For punishment to decrease more than protection, we require also that the response of the group be more "elastic" than that of the party. ${ }^{28}$ Proposition 6 lends some support to the notion that "strong" leaders may at times enjoy more freedom to choose policy. It also provides a rationale for institutions such as official immunity, which presumably strengthen politicians by insulating them from attacks.

Perhaps the more interesting aspect of these results is that, even under

\footnotetext{
${ }^{28}$ This in turn requires that $C^{\prime \prime}$ be small enough relative to $K^{\prime \prime}$ so that the group has a cost function that is relatively less convex.
} 
a rather stringent set of assumptions (additively separable preferences, $\lambda^{\prime}<0$, etc.), we cannot rule out perverse effects of presidential rents or presidential strength. In contrast, however, we showed that rents to the political party unambiguously improve policy making under nasty pressure groups. This difference in the effects of parameter changes is related to the assumption that the president and the party are called to play in different stages of the game. This choice reflects an asymmetry between party and president: while both enjoy office and are subject to electoral discipline, the president is the sole object of group pressure. The reason is that in our model, the president concentrates all the decision powers and party members cannot be attacked by the pressure group. The fact that the political party can be made up of a large number of individuals, all of them less prominent than the policy maker, makes this assumption plausible. ${ }^{29}$ In other words, this section brings out an important message of the model: the political party is different from the policy maker. This is in contrast to the public choice approach (e.g., Mueller 1989) and the models of partisan electoral competition (see, e.g., Persson and Tabellini 2000).

From a public policy point of view, the contrast between this subsection and the previous one is in itself informative because it suggests that acting on first-stage players is more reliable than acting on the president. For example, and to cite an existing debate in most transition democracies, it may be more reliable to try to make punishment through the media more difficult (by, e.g., making the media industry more competitive) than to grant extra immunity to policy makers. ${ }^{30}$ Although some initial amounts of immunity might be desirable, further enhancements of it require some reassurance about the technology (e.g., about the relative convexity of the cost functions of the group and the party). The effect of more competition in the media is more reliable in the sense that it does not depend on such considerations.

\section{Welfare and Political Parties}

A basic result concerning political parties is as follows.

Proposition 7. The equilibrium level of distortion with a political party enjoying positive rents is always lower than the equilibrium level when there is no party (or the party has no rents).

\footnotetext{
${ }^{29}$ In a previous version of the paper, we experimented with a political party with $N$ members. Clearly, as $N$ increases, it becomes more costly for the pressure group to maintain a given level of harassment on each member of the party.

${ }^{30}$ There is wide variation in parliamentary immunity laws across countries, and arguments similar to capture by threat are often made in their support. Amnesty International reports a number of politically motivated judicial rulings and the role of parliamentary immunity in protecting dissent (see, e.g., http://web.amnesty.org/ai.nsf/THEMES/ TRIALS)
} 
Proof. See Appendix A.

This proposition establishes that the existence of the party has benefits in terms of the quality of decision making. The decision to have a party with positive rents will then depend on the social welfare implications of better expected policies and on the costs of rents.

Assume that the citizens can adjust the level of rents accruing to the political party in a stage previous to that in which the pressure group and the party play $j^{*}$ and $s^{*}$. Citizens take into account the whole development of the game following their choice of rents. In other words, they construct a mapping from rent levels to equilibrium distortion and expected social welfare. Under a realized shock $\theta$, citizens get a social surplus $Z(\theta, P)$ when policy $P$ is implemented. We assume that, for every level $\theta, Z\left(\theta, P^{G}\right)>Z\left(\theta, P^{B}\right), Z^{\prime}\left(\theta, P^{G}\right)>Z^{\prime}\left(\theta, P^{B}\right)$, and $Z^{\prime}(\theta, P)<0$. These conditions imply that both the absolute and the marginal damage to welfare of a given shock are lower when good policies are chosen. Besides, larger shocks create larger welfare losses. The public cost of funds is given by the function $\Phi(w)$. The function $\Phi$ satisfies $\Phi(0)=0$, $\Phi^{\prime}(0)=0, \Phi^{\prime}(w)>0$ for $w>0$, and $\Phi^{\prime \prime} \geq 0$. The problem for the citizens is then to maximize expected social welfare with respect to $w$, as given by the following expression:

$$
Y=\int_{0}^{\theta^{*}} Z\left(\theta, P^{B}\right) \lambda(\theta) d \theta+\int_{\theta^{*}}^{1} Z\left(\theta, P^{G}\right) \lambda(\theta) d \theta-\Phi(w) .
$$

The FOC for this problem is

$$
\left[Z\left(\theta^{*}, P^{B}\right)-Z\left(\theta^{*}, P^{G}\right)\right] \lambda\left(\theta^{*}\right) \frac{d \theta^{*}}{d w}-\Phi^{\prime}=0 .
$$

The SOC is in Appendix B.

Proposition 8 . The public will always provide the political party with a positive level of rents.

Proof. See Appendix A.

The proof shows that, because at low levels of $w$ the marginal benefit of giving rents to the political party exceeds the marginal cost, the public is always better off when the political party accompanies the president and enjoys rents. Intuitively, the equilibrium level of rents trades off the advantages in terms of social welfare of making $P^{G}$ more likely with the costs of rents.

A potential criticism to this formulation is that presidential rents are assumed to be both exogenous and free. If this is not the case, a legitimate question is whether society would still choose to give rents to the political party if it also has the choice of giving rents to the president. The problem is very similar to the one presented above. One difference between party and presidential rents is that the latter have both a direct 
effect (the president is keener to retain office) and an indirect effect (the party and the pressure group will change net punishment). A second difference is that party rents are, in some sense, cost-effective. They induce benefits to the president only when good policies are chosen, whereas presidential rents are paid to him contingent on the electoral result, regardless of his policy choice. The party acts as a controller paid by the people. There are similarities between the political party in our model and the external supervisor in Kofman and Lawarree (1993). In their model the introduction of an external supervisor who, just like our political party, is costly but not capturable limits the possibility that the internal supervisor is captured. The possibility of capturing the president by threat in our model is reduced by the introduction of the political party. ${ }^{31}$

A second potential criticism is that a more general formulation of the way in which the group's attacks affect outcomes may reduce the value of giving rents to the party. In a richer model, for example, one could allow attacks to have an impact on the chances of reelection of the party and not just on the utility of the president, as well as allow for party insurance to make such attacks less effective. These extensions would be useful in evaluating whether the benefits of having a party isolated in this paper (the party as an insurance provider) are enough to compensate for any potential costs (e.g., the party as a source of help for presidential cover-ups). There seems to be anecdotal evidence for both stories, so we expect policy discussions on the level of rents to be given to political parties to take both of them into account. ${ }^{32}$

More generally, it should be noted that there may be legal or cultural constraints on the amount of rents that a single individual can receive, even when they have positive incentive effects. In such a case, giving rents to the party could be a way to circumvent this and an indirect way

\footnotetext{
${ }^{31}$ A caveat must be made, however, when the function for the cost of rents has the form $\Omega(w+m)$. One cannot rule out a priori a case in which presidential rents are more effective at reducing the distortion than party rents for an initial set of values. If marginal costs rise fast enough, a solution with no party rents cannot be ruled out even when the presence of the party improves policy making. It is worth emphasizing, however, that it is unlikely that the marginal effect of presidential rents is still larger than the effect of the first unit of party rents at the level at which society has decided to stop increasing the rents given to those in power. Thus we expect to observe party rents in equilibrium.

${ }^{32}$ During the Clinton impeachment, some observers argued that the Democratic party was helping the president cover up for his crimes just to remain in power. Others argued that the Democrats were providing the president with a legitimate defense. The most influential in this second camp was publisher Larry Flynt of Hustler magazine, who accused the Republicans of politically motivated attacks. To "prove" that the Republicans did not really object to Clinton's activities, he offered a million dollars for information on the sexual escapades of Republican members of Congress involved in the impeachment. This led to the disclosure of information on the personal life of the speaker-elect of the House, Bob Livingston $(\mathrm{R})$, which led to his resignation.
} 
of affecting the president's choices. Note that the party can always avoid such cultural constraints by adding new members.

\section{Conclusions}

We study a simple model of endogenous policy formation when there is electoral discipline and groups can use pressure. Thus, in contrast to the traditional approach in the interest group literature started by Stigler (1971) and Peltzman (1976), groups in our model are "nasty" in the sense that they can threaten to punish policy makers who refuse to do them favors. The approach is promising since there is ample anecdotal evidence that violence (including murder), legal harassment, and smear campaigns in the media have all been used, at one point or another, by groups trying to influence policy. A basic prediction of our model is that even a perfectly honest policy maker will deliver society's preferred policy less often than when pressure groups are inactive. This result is related to a large literature in political economy seeking to explain delay or failure to adopt socially beneficial economic policies (e.g., Alesina and Drazen 1991). Our model of capture by threat provides an alternative explanation for why reforms are delayed: policy makers fear punishment, so they deliver the good policy only when the electoral prize for it is high enough. Furthermore, the model can generate an empirical profile similar to that of models based on wars of attrition, where crisis makes reforms more likely (e.g., Drazen and Grilli 1993).

Our model shows how a number of factors not usually stressed in the literature will affect policy outcomes. It suggests, for example, that bad policies will be observed more frequently in countries in which the judiciary system is not independent or violence is common and cheap, giving the group increased access to threat technologies. Similarly, society's perception of what is acceptable behavior on the part of politicians will also affect policy. Insofar as this is a choice, countries may rationally choose not to be very puritan and decide that a politician's record of marital infidelity, for example, is not a matter of public concern. Perhaps more important, society could also discourage collusion in the media industry, enforcing strict antitrust laws so as to make it more expensive for a group's smear campaign to reach a large section of public opinion. The model also makes a distinction between factors that have a clear-cut effect on policy determination, such as those affecting pressure groups and other first-stage players, and factors with ambiguous effects, such as those affecting policy makers. Among these are institutions used in a variety of countries granting legal immunity 
to officials. They can be rationalized as aiming to insulate policy makers from threats. ${ }^{33}$

An important implication of capture by threat concerns the rewards to public life. In the standard model in which groups offer bribes to influence policy, officials can only be made better off by the presence of groups. For a given wage in the public sector, the presence of groups offering bribes will make entering public life more attractive. If the public and the private sectors were competing for applicants with varying ability levels, we would expect to see higher-ability public officials when there is capture through bribes. When groups are "nasty," however, elected officials can experience only a fall in income when groups become active. Thus public life will be attractive only to candidates whose opportunity wage in the private sector is low. This tendency to have lowability policy makers in environments in which groups punish instead of give bribes is of interest because it could provide an explanation for why violence and inefficient policies go together. Although a full treatment of these issues requires an entry stage, something that is left for future research, the essential departure from the previous literature is the fact that the instrument of the groups is no longer optional for officials (because bribes can be rejected whereas threats cannot be ignored) and that this instrument lowers-rather than raises-the politician's payoff.

Finally, the model naturally introduces a role for political parties. We show that the presence of a political party that cares for reelection has beneficial effects on the choice of policies by a president under pressure from nasty interest groups. In other words, the costs of a party could be more than compensated by the benefits of having a government more insulated from the threats of the pressure groups, a view that echoes that of Alexis de Tocqueville, who viewed political parties as "an evil inherent in free government." In contrast to most of the previous literature, our model emphasizes the differences between the political party and the policy maker. The fundamental characteristics of the political party are that its members are more expensive to punish for the pressure group than the president, that they enjoy rents only if the president is reelected, and that they can observe the policies he delivers better than the public. Thus rents for politicians in power are valuable for reasons other than the efficiency wage ones emphasized by Becker and Stigler (1974). The role of the political party in our model is similar to that played by the external supervisor in the literature on collusion in hierarchical agency (e.g., Kofman and Lawarree 1993).

\footnotetext{
${ }^{33}$ One recent instance of debate about immunity took place in June 2002, when legal protection was requested by the president of the Central Bank in Argentina-a country in which restructuring of the banking industry is necessary (see "Peronists Divided," 2002).
} 


\section{Appendix A}

Proof of Lemma 1

Part $a$ is direct from examination of the president's expected utility function. In part $b, \hat{\theta}$ satisfies $\Delta F(\theta, P)=h / m$. As the left-hand side is continuously differentiable and monotonically increasing in $\theta$, whereas the right-hand side is so in $h$, it follows that $\hat{\theta}(h)$ is continuously differentiable and monotonically increasing.

\section{Proof of Lemma 2}

The first sentence in part $a$ follows from the satisfaction of the conditions for the implicit function theorem in the interval $(0, \bar{s})$. We derive the existence of a value $\bar{s}$ later. The remainder of part $a$ follows from the characterization of the first-order comparative static effects of $s$ on $\hat{j}$ given by (with $\hat{\theta}=\hat{\theta}(h)$ and the fact that $d^{2} \hat{\theta} / d h^{2}=0$ from linearity of $F(\theta, P)$ in $\left.\theta\right)$,

$$
\frac{d \hat{j}}{d s}=\frac{\lambda^{\prime}(\hat{\theta})(d \hat{\theta} / d h)^{2} \Pi}{\lambda^{\prime}(\hat{\theta})(d \hat{\theta} / d h)^{2} \Pi-C^{\prime \prime}}>0 .
$$

The slope of $\hat{j}(s)$ (for $s<\bar{s}$ ) adopts some value in the interval $(0,1)$ as $C^{\prime \prime}(j)>$ 0 .

To see that $\bar{s}$, if existing, must be positive, note that $C^{\prime}(0)=0$, so that for an arbitrarily small level of $s$ the marginal benefits of punishment as determined by the FOC in (1) are greater than the marginal costs (even when, for any $j<$ $s$, the marginal benefit of punishment is zero). To see that $\bar{s}$ must exist and that $\hat{j}(\bar{s})>\bar{s}$, imagine a point $(\tilde{s}, \hat{j}(\tilde{s}))$ such that $\hat{j}(\tilde{s})=\tilde{s}$ (i.e., $\hat{j}(s)$ intersects the 45 degree line at such a point). The pressure group is then incurring costs $C(\tilde{s})$ for nothing since $\hat{\theta}(0)=0$, and the group is getting less than it could attain by doing nothing. This is true, by continuity of the expected profit function, for an interval $(\bar{s}, \tilde{s}]$ such that $\bar{s}<\tilde{s}$ and $\hat{j}(\bar{s})>\bar{s}$. Therefore, at $\bar{s}$ the best response jumps down to zero.

Part $b$ follows.

\section{Proof of Lemma 3}

Existence of a continuously differentiable function $\hat{s}(j)$ follows from the satisfaction of the conditions for the implicit function theorem. Clearly, if $j=0$, there is no gain in setting $s>0$, so $\hat{s}(0)=0$. The first-order comparative static effects of $j$ on $\hat{s}$ can be characterized by rewriting (3) in terms of $\hat{s}(j)$ and differentiating with respect to $j$ to obtain

$$
\frac{d \hat{s}}{d j}=\frac{A}{A+K^{\prime \prime}}>0
$$

where

$$
A=\left[\Delta F^{\prime}(\hat{\theta}, P)\left(\frac{d \hat{\theta}}{d h}\right)^{2} \lambda(\hat{\theta})+\Delta F(\hat{\theta}, P) \lambda^{\prime}(\hat{\theta})\left(\frac{d \hat{\theta}}{d h}\right)^{2}\right] w
$$

The sign follows from the fact that the denominator is positive (from the SOC), 
and the numerator is positive as well, if marginal returns to protection are decreasing when intersecting marginal costs. Then $d \hat{s} / d j<1$ whenever $K^{\prime \prime}>0$.

\section{Proof of Proposition 1}

In part $a, \hat{s}^{-1}(\bar{s}) \geq \hat{j}(\bar{s})$ is necessary for the response functions to intersect because it rules out the possibility that $\hat{j}(s)$ lies entirely above $\hat{s}^{-1}(s)$ in $[0, \bar{s}]$. Sufficiency follows when (i) both functions are continuous and strictly increasing and (ii) $j^{\circ}>0$.

In part $b$, the intersection of the functions $\hat{j}(s)$ and $\hat{s}^{-1}(s)$ in the space $(s, j)$ can happen only above the 45 -degree line because $\hat{j}(s)$ lies entirely above it.

\section{Proof of Proposition 2}

Part $a$ follows from the definition of the president's strategies and the fact that $\hat{\theta}(h)$ is a function mapping net punishment into $[0,1]$.

Part $b$ follows from part $a$ of this proposition and part $b$ of proposition 1 .

Proof of Proposition 3

Denote the expected payoff of a winning presidential candidate as $E U^{g r}$ when the group is active and $E U$ when it is not. The term $E U^{g r}$ is given by three elements: the rents earned in the current period, the punishment received, and the (for simplicity, undiscounted) rents received in the next period if reelection takes place. Because the rents earned in the current period play no role, we ignored them in our model as presented in Section III. The relevant payoff is then that accruing contingent on policy choice, given by

$$
E U^{g r}=\int_{0}^{\theta^{*}}\left[1-F\left(\theta, P^{B}\right)\right] m \lambda(\theta) d \theta+\int_{\theta^{*}}^{1}\left\{\left[1-F\left(\theta, P^{G}\right)\right] m-h^{*}\right\} \lambda(\theta) d \theta .
$$

The first term expresses the expected rents when the president chooses $P^{B}$ across all states for which he chooses it. The second term expresses the expected rents when the president chooses $P^{G}$, net of the disutility from punishment, across all states for which he does choose $P^{G}$. In turn, $E U$ is given by

$$
\begin{aligned}
E U & =\int_{0}^{1}\left[1-F\left(\theta, P^{G}\right)\right] m \lambda(\theta) d \theta \\
& =\int_{0}^{\theta^{*}}\left[1-F\left(\theta, P^{G}\right)\right] m \lambda(\theta) d \theta+\int_{\theta^{*}}^{1}\left\{\left[1-F\left(\theta, P^{G}\right)\right] m\right\} \lambda(\theta) d \theta .
\end{aligned}
$$

The assumption that $F\left(\theta, P^{G}\right)<F\left(\theta, P^{B}\right)$ and part $b$ of proposition 1 (showing that $h^{*}>0$ ) imply that both the first and the second terms of $E U$ are larger than those of $E U^{g r}$. Hence $E U>E U^{g r}$.

\section{Proof of Proposition 4}

A pair of functions $j^{*}(w)$ and $s^{*}(w)$ exist and are continuously differentiable since the system formed by the equations (1) and (3) satisfies the conditions for the 
implicit function theorem. Using the implicit functions and differentiating equations (1) and (3) with respect to $w$, we get a system

$$
\begin{aligned}
& a \frac{d j^{*}}{d w}-b \frac{d s^{*}}{d w}=e, \\
& c \frac{d j^{*}}{d w}-d \frac{d s^{*}}{d w}=f .
\end{aligned}
$$

The reader can check that $a<0, b<0, c>0$ (when marginal returns to protection are decreasing), $d>0, e=0, f<0$, and the determinant $-a d+b c$ is positive. Hence, the solutions are $d j^{*} / d w=b f /(-a d+b c)>0$ and $d s^{*} / d w=a f /(-a d+$ $b c)>0$. Moreover, $d h^{*} / d w=C^{\prime \prime} f /(-a d+b c)<0$ whenever $C^{\prime \prime}>0$. Thus, from part $b$ of lemma $1, \theta^{*}$ is diminishing in $w$.

\section{Proof of Proposition 5}

Analogous to that of proposition 4 . The differentiation, with respect to $\beta$, of the system given by (1) and (3)-written for functions $j^{*}(\beta)$ and $s^{*}(\beta)$-yields a system of two equations in two unknowns: $d j^{*} / d \beta$ and $d s^{*} / d \beta$. The determinant of the system is strictly positive when the SOCs for the party and the pressure group hold as strict inequalities. We get solutions

$$
\frac{d j^{*}}{d \beta}=\frac{-d e+b f}{-a d+b c}<0 ; \quad \frac{d s^{*}}{d \beta}=\frac{-c e+a f}{-a d+b c}<0 .
$$

The reader can check that $a<0, b<0, c>0, d>0, e>0$, and $f=0$. Then

$$
\frac{d h^{*}}{d \beta}=\frac{(c-d) e}{-a d+b c}=\frac{-K^{\prime \prime} \times Q^{\prime}}{-a d+b c}<0 ;
$$

that is, higher punishment costs imply lower net punishment and, hence, lower distortion.

Proof of Proposition 6

We show the analysis of changes in $m$ (those of $v$ can be studied identically). Changes in $m$ have an effect on $\theta^{*}=\hat{\theta}\left[m, h^{*}(m)\right]$ given by

$$
\frac{\partial \hat{\theta}\left(m, h^{*}\right)}{\partial m}+\frac{\partial \hat{\theta}\left(m, h^{*}\right)}{\partial h^{*}} \frac{d h^{*}}{d m}=-\frac{h^{*}}{\Delta F^{\prime}(\theta, P) m^{2}}+\frac{1}{\Delta F^{\prime}(\theta, P) m} \frac{d h^{*}}{d m} .
$$

The direct effect, given by the first term, is negative. Immediate algebra shows that, for the overall effect to be negative, it is required that $d h^{*} / d m<h^{*} / m$.

To understand the nature of this requirement, we derive $d h^{*} / d m$ and analyze its sign. A pair of functions $j^{*}(m)$ and $s^{*}(m)$ exist and are continuously differentiable since the system formed by the equations (1) and (3) satisfies the conditions for the implicit function theorem. Writing the system for the implicit functions and differentiating with respect to $m$, we get a system analogous to that in the proof of proposition 4, with unknowns $d j^{*} / d m$ and $d s^{*} / d m$ and solutions $d j^{*} / d m=(-d e+b f) /(-a d+b c)$ and $d s^{*} / d m=(-c e+a f) /(-a d+b c)$. Conditions $C^{\prime \prime}>0, K^{\prime \prime}>0$, and $\lambda^{\prime}(\theta)<0$ and assuming that the marginal returns to protection 
are decreasing in equilibrium imply, as the reader can check, that $a<0, b<0$, $c>0, d>0$,

$$
e=-\left[\lambda^{\prime}\left(\theta^{*}\right) \frac{\partial \hat{\theta}\left(m, h^{*}\right)}{\partial m} \frac{\partial \hat{\theta}\left(m, h^{*}\right)}{\partial h^{*}}+\lambda\left(\theta^{*}\right) \frac{\partial^{2} \hat{\theta}\left(m, h^{*}\right)}{\partial h^{*} \partial m}\right] \Pi
$$

has an indeterminate sign, and $f>0$. The determinant $-a d+b c$ is positive. We have that

$$
\frac{d h^{*}}{d m}=\frac{(-d+c) e+(b-a) f}{-a d+b c}=\frac{-K^{\prime \prime} e+f C^{\prime \prime}}{-a d+b c}
$$

As $f>0$, it follows that $d h^{*} / d m<0$-reinforcing the direct effect-iff

$$
e=\left[\lambda\left(\theta^{*}\right)+\theta^{*} \lambda^{\prime}\left(\theta^{*}\right)\right] \frac{\Pi}{\Delta F^{\prime}(\theta, P) m^{2}}>\frac{f C^{\prime \prime}}{K^{\prime \prime}}>0 .
$$

This is more likely to hold when the density over shocks is relatively flat around $\theta^{*}$-making $e$ larger-and when $K^{\prime \prime}$ is large relative to $C^{\prime \prime}$. Even when the indirect effect is adverse, the direct effect will dominate iff

$$
e>\frac{1}{K^{\prime \prime}}\left[f C^{\prime \prime}-\frac{h^{*}}{m}(-a d+b c)\right]
$$

Proof of Proposition 7

In the absence of a political party or when $w=0$, the equilibrium level of distortion is $\theta^{*}=j^{\circ} / \Delta F^{\prime}(\theta, P) m$. When the party is present and enjoys rents $w>0$, that level is

$$
\frac{j^{*}-s^{*}}{\Delta F^{\prime}(\theta, P) m}<\frac{j^{\circ}}{\Delta F^{\prime}(\theta, P) m}
$$

from the fact that $\hat{d j} / d s<1$.

\section{Proof of Proposition 8}

Proposition 4 implies $d \theta^{*} / d w<0$, and therefore the first term in equation (5) is positive at $w=0$ and the second is zero. Any intersection of marginal costs with marginal returns will then happen at $w>0$.

\section{Appendix B}

Second-Order Condition for the Pressure Group's Problem

Under linearity of $F(\theta, P)$ in $\theta$, the SOC is

$$
\lambda^{\prime}[\hat{\theta}(h)]\left(\frac{d \hat{\theta}}{d h}\right)^{2} \Pi-C^{\prime \prime}<0,
$$

which holds under our assumptions on $\lambda^{\prime}$ and $C^{\prime \prime}$. 
Second-Order Condition for the Party's Problem

Under linearity of $F(\theta, P)$ in $\theta$, differentiating (3) with respect to $s$ yields (with $\hat{\theta}=\hat{\theta}(h))$

$$
-\left[\Delta F^{\prime}(\hat{\theta}, P) \lambda(\hat{\theta})+\Delta F(\hat{\theta}, P) \lambda^{\prime}(\hat{\theta})\right]\left(\frac{d \hat{\theta}}{d h}\right)^{2} w-K^{\prime \prime}<0,
$$

where the sign of the inequality follows when $K^{\prime \prime}$ is high enough or when marginal returns are decreasing in equilibrium.

Second-Order Condition for the Citizens' Problem

Under linearity of $F(\theta, P)$ in $\theta$, the SOC is

$$
\left[\Delta Z^{\prime}\left(\theta^{*}, P\right) \lambda\left(\theta^{*}\right)+\Delta Z\left(\theta^{*}, P\right) \lambda^{\prime}\left(\theta^{*}\right)\right]\left(\frac{d \theta^{*}}{d w}\right)^{2}-\Phi^{\prime \prime}<0,
$$

where $\Delta Z^{\prime}\left(\theta^{*}, P\right)=Z^{\prime}\left(\theta^{*}, P^{B}\right)-Z^{\prime}\left(\theta^{*}, P^{G}\right)$ and $\Delta Z\left(\theta^{*}, P\right)=Z\left(\theta^{*}, P^{B}\right)-Z\left(\theta^{*}\right.$, $\left.P^{G}\right)$. The sign of the inequality follows when $\Phi^{\prime \prime}$ is high enough or when marginal returns are decreasing in equilibrium.

\section{References}

Acemoglu, Daron, and Robinson, James A. "Inefficient Redistribution." American Polit. Sci. Rev. 95 (September 2001): 649-61.

Alesina, Alberto, and Drazen, Allan. "Why Are Stabilizations Delayed?" A.E.R. 81 (December 1991): 1170-88.

Alesina, Alberto, and Spear, Stephen E. "An Overlapping Generations Model of Electoral Competition.” J. Public Econ. 37 (December 1988): 359-79.

Baron, David P. "Service-Induced Campaign Contributions and the Electoral Equilibrium.” Q.J.E. 104 (February 1989): 45-72.

Becker, Gary S. "A Theory of Competition among Pressure Groups for Political Influence.” Q.J.E. 98 (August 1983): 371-400.

Becker, Gary S., and Stigler, George J. "Law Enforcement, Malfeasance, and Compensation of Enforcers.” J. Legal Studies 3 (January 1974): 1-18.

Besley, Timothy, and Coate, Stephen. "Lobbying and Welfare in a Representative Democracy." Rev. Econ. Studies 68 (January 2001): 67-82.

Caillaud, Bernard, and Tirole, Jean. "Parties as Political Intermediaries." Manuscript. Toulouse: Inst. Economie Industrielle, 2001.

Caselli, Francesco, and Morelli, Massimo. "Bad Politicians.” J. Public Econ. (2003), in press.

Coate, Stephen, and Morris, Stephen. "On the Form of Transfers in Special Interests.” J.P.E. 103 (December 1995): 1210-35.

Cremer, Jacques. "Cooperation in Ongoing Organizations." Q.J.E. 101 (February 1986): 33-49.

Cutler, David, and Gruber, Jonathan. "Health Policy in the Clinton Era: Once Bitten, Twice Shy.” Working Paper no. 8455. Cambridge, Mass.: NBER, September 2001.

Dal Bó, Ernesto; Dal Bó, Pedro; and Di Tella, Rafael. "Plata o Plomo?: Bribes and Threats in a Theory of Political Influence.” Working Paper no. 28. Providence, R.I.: Brown Univ., Dept. Econ., 2002. 
Drazen, Allan. Political Economics in Macroeconomics. Princeton, N.J.: Princeton Univ. Press, 2000.

Drazen, Allan, and Grilli, Vittorio. "The Benefit of Crises for Economic Reforms." A.E.R. 83 (June 1993): 598-607.

Fernández, Raquel, and Rodrik, Dani. "Resistance to Reform: Status Quo Bias in the Presence of Individual-Specific Uncertainty." A.E.R. 81 (December 1991): 1146-55.

Fiorina, Morris, and Noll, Roger. "Voters, Bureaucrats and Legislators: A Rational Choice Perspective on the Growth of Bureaucracy." J. Public Econ. 9 (April 1978): 239-54.

Grossman, Gene M., and Helpman, Elhanan. "Protection for Sale." A.E.R. 84 (September 1994): 833-50.

Harrington, Joseph E., Jr. "The Role of Party Reputation in the Formation of Policy." J. Public Econ. 49 (October 1992): 107-21.

Jones, Philip R., and Hudson, John. "The Role of Political Parties: An Analysis Based on Transaction Costs." Public Choice 94 (January 1998): 175-89.

Kofman, Fred, and Lawarree, Jacques. "Collusion in Hierarchical Agency." Econometrica 61 (May 1993): 629-56.

Ledyard, John O. "The Pure Theory of Large Two-Candidate Elections." Public Choice 44, no. 1 (1984): 7-41.

Lora, Eduardo. "What Makes Reform More Likely?” Working Paper no. 424. Washington: Inter-American Development Bank, 1998.

Mueller, Dennis C. Public Choice II. Cambridge: Cambridge Univ. Press, 1989.

"Obituary: Galina Starovoitova." Economist 349 (November 28, 1998): 92.

Peltzman, Sam. "Toward a More General Theory of Regulation." J. Law and Econ. 19 (August 1976): 211-40.

"Peronists Divided on the Granting of Immunity to the President of the Central Bank" (in Spanish). La Nación (Buenos Aires) (June 13, 2002).

Persson, Torsten, and Tabellini, Guido. Political Economics: Explaining Economic Policy. Cambridge, Mass.: MIT Press, 2000.

Przeworski, Adam. Democracy and the Market: Political and Economic Reforms in Eastern Europe and Latin America. Cambridge: Cambridge Univ. Press, 1991.

Schlesinger, Stephen C. Bitter Fruit: The Untold Story of the American Coup in Guatemala. London: Sinclair Browne, 1982.

Schlozman, Kay Lehman, and Tierney, John T. "More of the Same: Washington Pressure Group Activity in a Decade of Change." J. Politics 45 (May 1983): 351-77.

Shepsle, Kenneth A., and Nalebuff, Barry. "The Commitment to Seniority in Self-Governing Groups.” J. Law, Econ., and Organization 6 (special issue; 1990): 45-72.

Snyder, James M., Jr., and Ting, Michael M. "An Informational Rationale for Political Parties.” Manuscript. Cambridge: Massachusetts Inst. Tech., 2000.

Solá, J. Morales. "Secret Meetings with Judges." La Nacion (Buenos Aires) (October 18, 1998).

Stigler, George J. "The Theory of Economic Regulation." Bell J. Econ. and Management Sci. 2 (Spring 1971): 3-21.

Tirole, Jean. "Collusion and the Theory of Organizations." In Advances in Economic Theory: Sixth World Congress, edited by Jean-Jacques Laffont. Econometric Society Monograph no. 21. Cambridge: Cambridge Univ. Press, 1992.

U.S. Congress. Joint Economic Committee. "Pressures for Reform in the East European Economies.” 101st Cong., 1st sess., October 20, 1989. 
Van Natta, Don, Jr. “Clinton Asked Ex-Aides' Help to Buy House.” New York Times (September 25, 1999), p. B1.

Vidal, Gore. "Big Business Doesn't Care for Bill Clinton or the People. So It Pays Its Lawyers to Get Rid of Him.” Observer (London) (August 9, 1998).

Weingast, Barry R., and Marshall, William J. "The Industrial Organization of Congress; or, Why Legislatures, Like Firms, Are Not Organized as Markets." J.P.E. 96 (February 1988): 132-63.

Weingast, Barry R.; Shepsle, Kenneth A.; and Johnsen, Christopher. "The Political Economy of Benefits and Costs: A Neoclassical Approach to Distributive Politics." J.P.E. 89 (August 1981): 642-64.

Wittman, Donald. "Why Democracies Produce Efficient Results." J.P.E. 97 (December 1989): 1395-1424. 